\title{
Metabolic Syndrome Components and Risk Factors for Pancreatic Adenocarcinoma: A Case-Control Study in China
}

\author{
Qiao Wu Ge Chen Wen-ming Wu Li Zhou Lei You Tai-ping Zhang \\ Yu-pei Zhao
}

Department of General Surgery, Peking Union Medical College Hospital, Chinese Academy of Medical Sciences and

Peking Union Medical College, Beijing, China

\section{Key Words}

Metabolic syndrome $\cdot$ Pancreatic adenocarcinoma $\cdot$ Risk factors

\begin{abstract}
Background: Metabolic syndrome is a complex collection of interrelated conditions. Recent data have shown that metabolic syndrome may play a role in several cancers. Pancreatic adenocarcinoma is the fourth most common cause of death from cancer in the United States and the fifth in Europe. Despite the increasing numbers of published studies, the etiology of pancreatic adenocarcinoma is incompletely defined. Therefore, this paper aims to evaluate the risk factors for pancreatic adenocarcinoma. Methods: This was a case-control study of pancreatic adenocarcinoma patients who were referred to the Peking Union Medical College Hospital. Controls were randomly selected from an existing database of healthy individuals at the Health Screening Center. Data on metabolic syndrome, pancreatic diseases, liver diseases, and a history of diabetes and history of hypertension were collected either by conducting a retrospective review of the patients' records and health examination reports or by interview. Results: A history of smoking $(\mathrm{OR}=2.981)$, diabetes $(O R=2.421)$, cholecystolithiasis $(O R=5.453)$, or chronic
\end{abstract}

pancreatitis $(O R=28.264)$ as well as the levels of fasting blood glucose $(O R=4.241)$, total cholesterol $(O R=1.793)$, and apolipoprotein $A(O R=36.065)$ were significantly related to pancreatic adenocarcinoma. Conclusions: Cholelithiasis, chronic pancreatitis, and certain metabolic syndrome components are potential risk factors for the development of pancreatic adenocarcinoma.

Copyright $\odot 2012$ S. Karger AG, Basel

\section{Introduction}

Pancreatic adenocarcinoma is a highly fatal cancer of the pancreatic epithelium. Owing to the paucity of effective methods for diagnosis, most pancreatic adenocarcinoma patients present with locally advanced or metastatic disease at the time of diagnosis $[1,2]$. As a result, the overall 5-year survival rate is less than $5 \%$, which is lower than that for any other type of cancer [3]. Even following a margin-negative resection, pancreatic cancer patients have only a $22 \%$ chance for a 5 -year survival [4]. Early identification of individuals at high risk for pancreatic adenocarcinoma could have a marked impact on reducing morbidity and mortality. Several risk factors associated with pancreatic cancer have been identified, includ-

\section{KARGER}

Fax +4161306 1234

E-Mail karger@karger.ch

www.karger.com
(C) 2012 S. Karger AG, Basel

0012-2823/12/0864-0294\$38.00/0

Accessible online at:

www.karger.com/dig
Prof. Yu-pei Zhao

Department of General Surgery, Peking Union Medical College Hospital

Chinese Academy of Medical Sciences and Peking Union Medical College Beijing 100730 (China)

Tel. +86106529 6007, E-Mail zhao8028@263.net 
ing genetic factors [5], cigarette smoking [6-9], alcohol intake [10], chronic pancreatitis [11, 12], diabetes mellitus $[13,14]$, and obesity [15-17]. However, most of these risk factors were identified by systematic reviews of Western studies, and risk factors for pancreatic adenocarcinoma in China have rarely been reported.

Thus, the aim of this study was to perform a detailed evaluation of the relationship between components of metabolic syndrome or other possible risk factors and the occurrence of pancreatic adenocarcinoma in a cohort of men and women in China.

\section{Participants and Methods}

\section{Study Population and Design}

We conducted a hospital-based, case-control study including 840 subjects ( 210 patients with histologically confirmed pancreatic adenocarcinoma and 630 healthy controls) from the Peking Union Medical College Hospital (PUMCH), Beijing, China. This hospital is a major diagnosis and treatment hospital for pancreatic adenocarcinoma in China.

Using the PUMCH patient information database, we compiled a list of all patients who had been diagnosed with pancreatic adenocarcinoma between 2008 and 2011. Neuroendocrine tumors of the pancreas were excluded. Patients who had undergone a primary attempt at curative resection and whose diagnoses were confirmed by pathological examination were included in this study. We performed a manual retrospective review of the patients' records to collect demographic, clinical, and risk factor information. This review included a detailed assessment of the family history of cancer, personal medical history, hormone and medication intake, and occupational exposure to chemicals. The collection of data, including age, sex, demographic data, and a history of systemic diseases and gastrointestinal surgery, and a complete physical examination were conducted by the doctors prior to surgery. Other related information was collected by interviewing patients or their family members and was recorded by a physician using a structured data collection sheet. Such recording is routinely performed in our gastrointestinal oncology clinic, and the forms have been kept as a part of the patients' medical records. Age, sex, a history of hypertension and diabetes mellitus, HBV infection, metabolic syndrome, and previous cholecystectomy data were abstracted.

Using the Statistical Package for the Social Sciences software, version 13 (SPSS, Chicago, Ill., USA), controls were randomly selected from an existing database of healthy individuals at the Health Screening Center of PUMCH and were frequency-matched to cases by sex and exact age at a ratio of 3:1. The database consists of healthy individuals who are genetically unrelated family members, spouses, and friends of patients who had cancers other than gastrointestinal cancer. The Health Screening Center of PUMCH is one of the major centers providing routine physical examinations in Beijing, and those receiving examinations at this center are mostly native residents.

We performed a manual retrospective review of the health examination reports to collect demographic, clinical, and risk factor information for the controls. The collection of data, including age, sex, demographic data, and a history of systemic diseases and gastrointestinal surgery, and a complete physical examination were completed by doctors at the physical examination centers. Measurements of height without shoes and weight while clothed were recorded. Body mass index (BMI) values $\left(\mathrm{kg} / \mathrm{m}^{2}\right)$ were used as a measurement of obesity. Other related information was collected and recorded in a structured data collection sheet by the examining physicians using the same procedure as was used for the patients. The controls were interviewed between 2008 and 2011. Two participants were excluded from the study due to incomplete health examination records and loss to follow-up.

Cholelithiasis (including cholecystolithiasis, choledocholithiasis and hepatolithiasis) and chronic pancreatitis in all patients were diagnosed using data from clinical imaging studies (abdominal ultrasound, CT scan, ERCP and MRI) and by reviewing the patients' medical records. All patients underwent at least one of the aforementioned imaging studies. For control subjects, potential risk factors were determined based on abdominal ultrasound data and by reviewing the health examination reports. All of the controls had previously undergone ultrasound screening for the detection of stones.

This study was performed after receiving approval from the ethics committees of PUMCH, and informed consent was obtained from all participants.

\section{Laboratory Tests}

After overnight fasting, blood samples for laboratory examination were drawn via venipuncture from all study participants by clinical nurses. Serum lipids, including triglycerides (Tri), total cholesterol (TC), high-density lipoprotein (HDL), low-density lipoprotein (LDL), apolipoprotein A (Apo A), and apolipoprotein B (Apo B), were measured using a Hitachi Modular analytics system (Roche Modular DPP, Hitachi Ltd, Tokyo, Japan). The presence of HBsAg and anti-HBc was tested using a second-generation enzyme-linked immunosorbent assay (Abbott Laboratories, North Chicago, Ill., USA). Chronic hepatitis B infection was defined as the presence of both HBsAg and anti-HBc.

\section{Statistical Analysis}

Analyses were carried out using the SPSS, version 13.0. The Student's t test was used to evaluate differences in characteristics between the groups. A value of $\mathrm{p}<0.05$ was considered statistically significant. The univariate analysis results are expressed in terms of the odds ratio (OR) and 95\% confidence interval (CI). To evaluate the putative potential risk factors associated with pancreatic adenocarcinoma, risk factors with $p$ values $<0.05$ were further tested by multivariate logistic regression.

\section{Results}

We included 210 pancreatic adenocarcinoma cases and 630 controls in our analysis. The pancreatic adenocarcinoma patients and the control subjects had the same mean age $(59.3 \pm 11.5$ years), and there were no differences in the sex ratio between the two groups ( $\mathrm{p}=$ $1.000)$. 
Pancreatic adenocarcinoma patients had a significantly higher prevalence of chronic pancreatitis than controls $(16.2$ vs. $0.6 \%)$. In the univariate analyses, a history of smoking ( 34.8 vs. $24.4 \%$ ), diabetes ( 25.7 vs. $9.3 \%$ ), cholelithiasis (23.8 vs. $3.7 \%$ ) or cholecystectomy (6.2 vs. $2.9 \%)$ as well as heightened values of FBG (46.7 vs. $14.3 \%)$, TC (21.4 vs. $12.2 \%)$, Tri ( 40.5 vs. $31.6 \%$ ), LDL (20.5 vs. $12.7 \%$ ), Apo B (41.9 vs. $21.7 \%$ ) and BMI (53.3 vs. $43.1 \%)$ were significantly more associated with pancreatic adenocarcinoma patients than controls. Moreover, the levels of HDL (62.9 vs. $86.5 \%)$ and Apo A (62.5 vs. $98.5 \%)$ were lower among the patients than controls.

In the multivariate logistic regression analysis, a history of smoking $(\mathrm{OR}=2.981)$, diabetes $(\mathrm{OR}=2.421)$, cholecystolithiasis $(\mathrm{OR}=5.453)$, or chronic pancreatitis $(\mathrm{OR}=28.264)$ as well as the levels of fasting blood glucose $(\mathrm{OR}=4.241)$, total cholesterol $(\mathrm{OR}=1.793)$ and Apo $\mathrm{A}$ $(\mathrm{OR}=36.065)$ were correlated with pancreatic adenocarcinoma, but the remaining variables were not significantly associated with the development of pancreatic adenocarcinoma after adjustments were made for covariates (table 1). The estimated ORs of the above variables were adjusted for age and sex. Hypertension, HBV markers, and the levels of HDL, LDL, Tri, and Apo B were not significantly different between the pancreatic adenocarcinoma cases and controls (table 1).

\section{Discussion}

To our knowledge, this is the first Chinese hospitalbased case-control study to evaluate metabolic syndrome components, especially dyslipidemia, as risk factors for pancreatic adenocarcinoma. The results of this study provide evidence that certain metabolic syndrome components (diabetes, high FBG, TC and Apo A) as well as cigarette smoking, cholecystolithiasis and chronic pancreatitis are associated with an increased risk of pancreatic adenocarcinoma.

Diabetes is considered a major public health challenge in both industrialized and developing countries. A number of studies have found that diabetes is a significant risk factor for total cancer incidence and mortality and for some site-specific cancers $[18,19]$, notably breast and colorectal cancers and likely endometrial [18] and prostate cancers [18]. The relationship between diabetes and pancreatic adenocarcinoma remains controversial [20], but increasing epidemiological evidence supports the idea that long-standing diabetes has a role in the development of pancreatic adenocarcinoma $[13,14]$. A recent meta-analysis of 17 case-control studies and 19 cohort studies reported an overall relative risk of 1.82 (95\% CI 1.66-1.99) for pancreatic adenocarcinoma, and our findings are consistent with these results reported for nonChinese populations, as we found a 2.4-fold increased risk of pancreatic adenocarcinoma in patients with diabetes. In addition, we found that serum glucose level was associated with the incidence of pancreatic adenocarcinoma, and the study by Gapstur et al. [21] also found a link between plasma glucose concentration and pancreatic adenocarcinoma. Furthermore, this previous study provided evidence for a positive dose-response relationship between postload glycemia and mortality due to pancreatic adenocarcinoma.

Although the exact roles of diabetes and high serum glucose levels in pancreatic adenocarcinoma remain unclear, several biological mechanisms have been proposed to explain the potentially causal relationship between diabetes and cancer risk. Insulin resistance and subsequent hyperinsulinemia is a common phenomenon in diabetes patients [22], and in the hyperinsulinemic state, the exocrine cells of the pancreas are exposed to extremely high levels of insulin. Hennig et al. [23] found that pancreatic ductal cells are exposed to insulin concentrations that are 20 -fold higher than those present in the systemic circulation. Moreover, as a growth promoter, insulin may upregulate the production of insulin-like growth factor-1, which may result in enhanced cell proliferation and promote cancer development. It has also been shown that high-level exposure to insulin promotes the in vitro growth of the majority of human pancreatic cancers [24, 25], and the levels of markers of pancreatic ductal replication are increased synergistically in obese diabetic subjects. Another mechanism responsible may be an increase in oxidative stress, which could cause a permanent proinflammatory state that may reduce the intracellular antioxidant capacity and predispose the pancreas to malignant transformation [26]. Reactive oxygen species generated by diverse free radicals and oxidants can cause cell deoxyribonucleic acid (DNA) damage by direct oxidation or by interfering with cellular DNA repair. Reactive oxygen species can also form derivatives and alter intracellular homeostasis by reacting with proteins and lipids to favor the accumulation of mutations [27].

Given the significant link between diabetes and cancer risk, extensive attention has been paid to the role of antidiabetic drugs in cancer. Numerous epidemiological studies have demonstrated that metformin exhibits a protective effect by decreasing the incidence of various tumors and improving the prognosis of patients with 
Table 1. Risk factors for pancreatic adenocarcinoma: univariate and multivariate logistic regression analysis using the Fisher exact test

\begin{tabular}{|c|c|c|c|c|c|c|}
\hline & \multirow{2}{*}{$\begin{array}{l}\text { Controls } \\
\mathrm{n}(\%)\end{array}$} & \multirow{2}{*}{$\begin{array}{l}\text { Cases } \\
\mathrm{n}(\%)\end{array}$} & \multicolumn{2}{|l|}{ Univariate } & \multicolumn{2}{|c|}{ Multivariate } \\
\hline & & & $\mathrm{p}$ & OR (95\% CI) & $\mathrm{p}$ & OR $(95 \% \mathrm{CI})$ \\
\hline \multicolumn{7}{|l|}{ Age } \\
\hline$<50$ years & $111(17.6)$ & $37(17.6)$ & 1 (reference) & & & \\
\hline$\geq 50$ years & $519(82.4)$ & $173(82.4)$ & 1.000 & $1.000(0.664-1.507)$ & & \\
\hline \multicolumn{7}{|l|}{ Gender } \\
\hline Female & $261(41.4)$ & $87(41.4)$ & 1 (reference) & & & \\
\hline Male & $369(58.6)$ & $123(58.6)$ & 1.000 & $1.000(0.728-1.373)$ & & \\
\hline \multicolumn{7}{|l|}{ Smoking } \\
\hline No & $461(75.6)$ & $137(65.2)$ & 1 (reference) & & & \\
\hline Yes & $149(24.4)$ & $73(34.8)$ & 0.005 & $1.649(1.175-2.313)$ & 0.017 & $2.981(1.019-8.716)$ \\
\hline \multicolumn{7}{|l|}{ Alcohol drinking } \\
\hline No & $150(71.4)$ & 467 & 1 (reference) & & & \\
\hline Yes & $60(28.6)$ & 163 & 0.471 & $1.146(0.809-1.624)$ & & \\
\hline \multicolumn{7}{|c|}{$1.110(0.007 .021)$} \\
\hline HBsAg-/anti-HBc- & $308(48.9)$ & $117(55.7)$ & 1 (reference) & & & \\
\hline HBsAg+/anti-HBc+ & $16(2.5)$ & $6(0.9)$ & 1.000 & $0.987(0.377-2.584)$ & & \\
\hline HBsAg-/anti-HBc+ & $306(48.6)$ & $87(41.4)$ & 0.076 & $0.748(0.544-1.030)$ & & \\
\hline \multicolumn{7}{|l|}{ Diabetes mellitus } \\
\hline No & $572(90.8)$ & $156(74.3)$ & 1 (reference) & & & \\
\hline Yes & $58(9.3)$ & $54(25.7)$ & $<0.001$ & $3.414(2.264-5.148)$ & 0.013 & $2.421(1.074-5.458)$ \\
\hline \multicolumn{7}{|l|}{ Hypertension } \\
\hline No & $448(71.1)$ & $150(71.4)$ & 1 (reference) & & & \\
\hline Yes & $182(28.9)$ & $60(28.6)$ & 1.000 & $0.985(0.697-1.391)$ & & \\
\hline \multicolumn{7}{|l|}{ Cholecystolithiasis } \\
\hline No & $607(96.3)$ & $160(76.2)$ & 1 (reference) & & & \\
\hline Yes & $23(3.7)$ & $50(23.8)$ & $<0.001$ & $8.247(4.885-13.923)$ & $<0.001$ & $5.453(2.827-10.516)$ \\
\hline \multicolumn{7}{|l|}{ Cholecystectomy } \\
\hline No & $612(97.1)$ & $197(93.8)$ & 1 (reference) & & & \\
\hline Yes & $18(2.9)$ & $13(6.2)$ & 0.034 & $2.244(1.080-4.661)$ & 0.184 & $0.399(0.103-1.548)$ \\
\hline \multicolumn{7}{|l|}{ Chronic pancreatitis } \\
\hline No & $626(99.4)$ & $176(83.8)$ & 1 (reference) & & & \\
\hline \multirow{2}{*}{\multicolumn{7}{|c|}{$29.700(10.410-04.371)$}} \\
\hline & & & & & & \\
\hline$<5.70 \mathrm{mmol} / \mathrm{l}$ & $553(87.8)$ & $65(78.6)$ & 1 (reference) & & & \\
\hline$\geq 5.70 \mathrm{mmol} / \mathrm{l}$ & $77(12.2)$ & $45(21.4)$ & 0.002 & 1.959 (1.304-2.942) & 0.028 & $1.793(1.067-3.013)$ \\
\hline \multicolumn{7}{|l|}{ Tri } \\
\hline$<1.7 \mathrm{mmol} / \mathrm{l}$ & $431(68.4)$ & $125(59.5)$ & 1 (reference) & & & \\
\hline$\geq 1.7 \mathrm{mmol} / \mathrm{l}$ & $199(31.6)$ & $85(40.5)$ & 0.023 & $1.473(1.067-2.034)$ & 0.267 & $0.776(0.496-1.214)$ \\
\hline \multicolumn{7}{|l|}{ HDL } \\
\hline$<0.93 \mathrm{mmol} / 1$ & $545(86.5)$ & $132(62.9)$ & 1 (reference) & & & \\
\hline$\geq 0.93 \mathrm{mmol} / \mathrm{l}$ & $85(13.5)$ & $78(37.1)$ & $<0.001$ & $0.264(0.184-0.379)$ & 0.785 & $1.087(0.596-1.981)$ \\
\hline LDL & & & & & & \\
\hline$<3.63 \mathrm{mmol} / \mathrm{l}$ & $550(87.3)$ & $167(79.5)$ & 1 (reference) & & & \\
\hline$\geq 3.63 \mathrm{mmol} / \mathrm{l}$ & $80(12.7)$ & $43(20.5)$ & 0.009 & $1.770(1.176-2.665)$ & 0.411 & $0.721(0.331-1.571)$ \\
\hline FBG & & & & & & \\
\hline$<6.1 \mathrm{mmol} / \mathrm{l}$ & $540(85.7)$ & $112(53.3)$ & 1 (reference) & & & \\
\hline$\geq 6.10 \mathrm{mmol} / \mathrm{l}$ & $90(14.3)$ & $98(46.7)$ & $<0.001$ & $5.250(3.695-7.459)$ & $<0.001$ & $4.241(2.751-6.538)$ \\
\hline Apo A & & & & & & \\
\hline$<1 \mathrm{~g} / \mathrm{l}$ & $623(98.9)$ & $137(65.2)$ & 1 (reference) & & & \\
\hline$\geq 1 \mathrm{~g} / \mathrm{l}$ & $7(1.1)$ & $73(34.8)$ & $<0.001$ & $0.021(0.010-0.047)$ & $<0.001$ & $36.065(15.547-83.663)$ \\
\hline Apo B & & & & & & \\
\hline$<1 \mathrm{~g} / \mathrm{l}$ & $493(78.3)$ & $122(58.1)$ & 1 (reference) & & & \\
\hline$\geq 1 \mathrm{~g} / 1$ & $137(21.7)$ & $88(41.9)$ & $<0.001$ & $2.596(1.860-3.622)$ & 0.204 & $1.406(0.831-2.380)$ \\
\hline $\mathrm{BMI}$ & & & & & & \\
\hline$<25.0$ & $359(56.9)$ & $98(46.7)$ & 1 (reference) & & & \\
\hline$\geq 25.0$ & $271(43.1)$ & $112(53.3)$ & 0.01 & $1.514(1.106-2.072)$ & 0.368 & $1.893(0.472-7.600)$ \\
\hline
\end{tabular}

FBG $=$ Fasting blood glucose. 
cancer [28-30]. Furthermore, a population-based cohort study in Taiwan found that thiazolidinedione treatment was significantly associated with a reduced incidence of hepatocellular carcinoma [31]. In contrast, treatments that increase circulating insulin levels (e.g. sulfonylureas and exogenous insulin) have been associated with an increased risk of developing cancers [32]. The current study did not evaluate the effect of a single antidiabetic drug on pancreatic adenocarcinoma development because approximately $15.1 \%$ of the patients in our study population had been prescribed more than one type of antidiabetic drug. However, we plan to evaluate the roles of individual drugs in further research.

Hyperlipidemia, which is generally characterized by high serum levels of TC, Tri, and LDL and a low level of HDL, has been reported to be associated with the development of several cancers [33-36]. However, few studies have examined the association between lipid profiles and pancreatic adenocarcinoma, and this paucity of studies led us to question whether dyslipidemia could be a possible determinant of pancreatic adenocarcinoma risk. In the current study, we found that pancreatic adenocarcinoma risk was also associated with a more pronounced atherogenic lipid profile, i.e. high TC and low Apo A levels. There were 1.793- and 36.065-fold increases in risk associated with high TC values and low Apo A values, respectively, and these findings are generally consistent with previous epidemiologic evidence.

Several underlying mechanisms by which hyperlipidemia and carcinogenesis may be linked have been proposed. Increased levels of TC have been associated with increased circulating levels of proinflammatory cytokines, including TNF- $\alpha$, IL-1, and IL-6 $[37,38]$. Moreover, several other pathways that are considered vital for carcinogenesis, such as the sonic hedgehog and Akt pathways, are also cholesterol-sensitive [39, 40]. Apo A is the major component of HDL particles [41] and can reduce the levels of free TNF- $\alpha$, which results in attenuated tumor formation [42]. Low levels of Apo A may therefore contribute to inflammatory processes linked to tumor biology. For example, low Apo A levels were found to be associated with a higher risk of breast cancer [43], and for ovarian cancer, Apo A is one of the biomarkers that was shown to potentially improve early detection [44]. Apo A is more strongly linked to prostate cancer risk than Apo B [41], and we did not find any evidence for an association between pancreatic adenocarcinoma and other lipid components (Apo B, Tri, or LDL). However, it is possible that there are distinct etiological relationships between lipid profiles and pancreatic adeno- carcinoma. Based on the results of our retrospective cohort study, it is difficult to tease out the specific mechanism responsible for the link between Apo A levels and pancreatic adenocarcinoma risk, but the data described above suggest that dyslipidemias may play a role in pancreatic tract carcinogenesis through their inflammatory properties. However, further studies are needed to clarify this potential role.

In recent decades, accumulating evidence has identified long-standing, preexisting chronic pancreatitis, a rare inflammatory condition, as a strong risk factor for pancreatic cancer [12, 19, 45, 46]. Case-control studies have estimated the increased risk of pancreatic cancer for patients with chronic pancreatitis to range from 2 to $16 \%$ [47]. There was also a strong association between chronic pancreatitis and the risk of pancreatic cancer in our study, but the magnitude of the observed association was greater in our study, as we observed a 28.264-fold increased risk of pancreatic adenocarcinoma. The precise mechanism linking chronic pancreatitis and pancreatic cancer has not been completely defined and most likely involves numerous steps with increasing DNA damage and the development of pancreatic intraepithelial neoplasms prior to the development of frank malignancy. There is evidence of increased cell proliferation and premalignant changes associated with pancreatitis that may play a role in the development of pancreatic cancer [48]. Kras activity is present in nearly all pancreatic adenocarcinomas and may be an important link between benign and malignant disease. Moreover, this activity is one of the early genetic events that may potentiate the progression of chronic pancreatitis to pancreatic adenocarcinoma [49, 50]. In a mouse model, Kras mutations can lead to pancreatic intraepithelial neoplasm changes and eventually to pancreatic cancer [51].

Observational studies in humans have demonstrated the existence of relationships between several medical conditions, including cholecystitis [52], cholecystectomy [53], HBV infection [54] and ulcer gastrectomy [19], and an increased risk of pancreatic adenocarcinoma, but these findings have been somewhat contradictory. In our study, we observed a significant positive linear association between the risk of pancreatic adenocarcinoma and cholelithiasis ( $\mathrm{OR}=5.453)$. However, it has been previously noted that there may be a connection between cholelithiasis and chronic inflammation of the pancreas [55], and some autopsy studies have also reported a much higher prevalence of chronic pancreatitis in gallstone patients $[56,57]$. Given the possibility that the association between cholelithiasis and pancreatic 
adenocarcinoma may be confounded by chronic pancreatitis, we excluded patients who had chronic pancreatitis but found that chronic pancreatitis did not change the observed association (data not shown). Previous epidemiologic studies have suggested that pancreatic cancer risk may be elevated after cholecystectomy $[8,58$ 60]. The presumed increased release of cholecystokinin, which has a trophic effect on pancreatic acinar cells [62, 63], following cholecystectomy [61] may contribute to an increased risk of pancreatic cancer risk following gallbladder removal. Our findings do not support an important role for cholecystectomy in the carcinogenesis of pancreatic cancer, which is in line with the conclusions of most previous case-control studies on cholecystectomy.

Based on findings from epidemiologic studies, cigarette smoking has been firmly established as a risk factor for pancreatic adenocarcinoma $[64,65]$. Our findings are in agreement with the results of these population studies, as the prevalence of cigarette smoking in the current study was significantly higher among pancreatic adenocarcinoma patients than controls (34.8 vs. $24.4 \%$ ). However, our results did not support the previously observed relationships between pancreatic cancer and alcohol drinking [10], HBV infection and ulcer gastrectomy. The reasons for these inconsistencies across studies are unclear but may due to differences in study design or study populations or to inadequate control of confounding factors. Moreover, these reasons may also be able to explain the association between pancreatic adenocarcinoma and $\mathrm{BMI}$, which did not reach significance in the multivariate regression analysis.

There were several methodological strengths and limitations of the current study. First, our study was a hospital-based study performed at a single institution rather than a population-based study, and this design may have introduced a selection bias due to differential referral patterns. Second, diabetic patients may have received more than one type of antidiabetic drug, which may have complicated the situation; as a result, we did not evaluate the effect of individual antidiabetic drugs on pancreatic adenocarcinoma development. Third, this observational study did not explore the mechanisms by which risk factors may be related to pancreatic adenocarcinoma. However, these limitations were outweighed by several important strengths. First, we do not believe that we introduced an ascertainment bias by misdiagnosis, as all patients had pathologically confirmed pancreatic adenocarcinoma. Second, the control subjects were healthy individuals who had been selected from genetically unre- lated family members or spouses at the Heath Screening Central of PUMCH, and their reasons for participating in this study were not related to the risk factors being studied. Therefore, these control subjects represented the study base from which our cases were selected. Finally, the accuracy of the diagnostic confirmation of cancer and the risk factor data were of high quality, given that the detailed behavioral and epidemiologic data were prospectively and systematically collected by providers for all patients at their initial visit to the surgical department of PUMCH.

\section{Conclusions}

This study revealed that an increased likelihood of pancreatic adenocarcinoma was associated with metabolic syndrome components and several medical conditions. Of these factors, a history of cigarette smoking, diabetes, cholelithiasis, and chronic pancreatitis and high levels of FBG, TC, and Apo A were shown to independently increase the risk of pancreatic adenocarcinoma. These findings suggest that these metabolic syndrome components and medical conditions may serve as predictors of pancreatic adenocarcinoma. A better understanding of the underlying pathophysiology of the association between these risk factors and pancreatic adenocarcinoma may provide new insights into potential additive or synergistic effects of metabolic syndrome components, facilitate the development of pancreatic adenocarcinoma treatment modalities, and strengthen the clinical relevance for the treatment of patients who meet the criteria for this insidious syndrome.

\section{Acknowledgment}

This work was supported in part by a grant for the municipal key discipline of Beijing, China (HK100230446).

\section{Disclosure Statement}

The authors have no conflicts of interest to disclose. 


\section{References}

$\nabla_{1}$ Perrin MC, Terry MB, Kleinhaus K, Deutsch L, Yanetz R, Tiram E, Calderon R, Friedlander Y, Paltiel O, Harlap S: Gestational diabetes as a risk factor for pancreatic cancer: a prospective cohort study. BMC Med 2007;5: 25.

-2 Stoita A, Penman ID, Williams DB: Review of screening for pancreatic cancer in highrisk individuals. World J Gastroenterol 2011; 17:2365-2371.

3 Permuth-Wey J, Egan KM: Family history is a significant risk factor for pancreatic cancer: results from a systematic review and meta-analysis. Fam Cancer 2009;8:109-117.

$\checkmark 4$ Yeo CJ, Cameron JL, Lillemoe KD, Sitzmann JV, Hruban RH, Goodman SN, Dooley WC, Coleman J, Pitt HA: Pancreaticoduodenectomy for cancer of the head of the pancreas. 201 patients. Ann Surg 1995;221:721-731.

$\checkmark 5$ Brand RE, Lynch HT: Hereditary pancreatic adenocarcinoma. A clinical perspective. Med Clin North Am 2000;84:665-675.

-6 Kornmann M, Beger HG, Korc M: Role of fibroblast growth factors and their receptors in pancreatic cancer and chronic pancreatitis. Pancreas 1998;17:169-175.

7 Lukic S, Nikolic A, Alempijevic T, Popovic D, Sokic Milutinovic A, Ugljesic M, Knezevic S, Milicic B, Dinic D, Radojkovic D: Angiotensin-converting enzyme gene insertion/deletion polymorphism in patients with chronic pancreatitis and pancreatic cancer. Dig Surg 2011;28:258-262.

>8 Coughlin SS, Calle EE, Patel AV, Thun MJ: Predictors of pancreatic cancer mortality among a large cohort of United States adults. Cancer Causes Control 2000;11:915-923.

$\checkmark 9$ Iodice S, Gandini S, Maisonneuve P, Lowenfels AB: Tobacco and the risk of pancreatic cancer: a review and meta-analysis. Langenbecks Arch Surg 2008;393:535-545.

-10 Gapstur SM, Jacobs EJ, Deka A, McCullough ML, Patel AV, Thun MJ: Association of alcohol intake with pancreatic cancer mortality in never smokers. Arch Intern Med 2011;171: 444-451.

-11 Hassan MM, Bondy ML, Wolff RA, Abbruzzese JL, Vauthey JN, Pisters PW, Evans DB, Khan R, Chou TH, Lenzi R, Jiao L, Li D: Risk factors for pancreatic cancer: case-control study. Am J Gastroenterol 2007;102:26962707.

$\checkmark 12$ Raimondi S, Maisonneuve P, Lowenfels AB: Epidemiology of pancreatic cancer: an overview. Nat Rev Gastroenterol Hepatol 2009;6: 699-708.

$\checkmark 13$ Huxley R, Ansary-Moghaddam A, Berrington de Gonzalez A, Barzi F, Woodward M: Type-II diabetes and pancreatic cancer: a meta-analysis of 36 studies. Br J Cancer 2005;92:2076-2083.

-14 Everhart J, Wright D: Diabetes mellitus as a risk factor for pancreatic cancer. A metaanalysis. JAMA 1995;273:1605-1609.
15 Eberle CA, Bracci PM, Holly EA: Anthropometric factors and pancreatic cancer in a population-based case-control study in the San Francisco Bay area. Cancer Causes Control 2005; 16:1235-1244.

16 Larsson SC, Permert J, Hakansson N, Naslund I, Bergkvist L, Wolk A: Overall obesity, abdominal adiposity, diabetes and cigarette smoking in relation to the risk of pancreatic cancer in two Swedish populationbased cohorts. Br J Cancer 2005;93: 1310-1315.

17 Larsson SC, Orsini N, Wolk A: Body mass index and pancreatic cancer risk: a metaanalysis of prospective studies. Int J Cancer 2007;120:1993-1998.

18 Lee MY, Lin KD, Hsiao PJ, Shin SJ: The association of diabetes mellitus with liver, colon, lung, and prostate cancer is independent of hypertension, hyperlipidemia, and gout in Taiwanese patients. Metabolism 2012;61: 242-249.

19 Lipworth L, Zucchetto A, Bosetti C, Franceschi S, Talamini R, Serraino D, McLaughlin JK, La Vecchia C, Negri E: Diabetes mellitus, other medical conditions and pancreatic cancer: a case-control study. Diabetes Metab Res Rev 2011;27:255-261.

20 Wang F, Herrington M, Larsson J, Permert J: The relationship between diabetes and pancreatic cancer. Mol Cancer 2003;2:4.

21 Gapstur SM, Gann PH, Lowe W, Liu K, Colangelo L, Dyer A: Abnormal glucose metabolism and pancreatic cancer mortality. JAMA 2000;283:2552-2558.

22 Suzuki H, Li Y, Dong X, Hassan MM, Abbruzzese JL, Li D: Effect of insulin-like growth factor gene polymorphisms alone or in interaction with diabetes on the risk of pancreatic cancer. Cancer Epidemiol Biomarkers Prev 2008;17:3467-3473.

23 Hennig R, Ding XZ, Adrian TE: On the role of the islets of Langerhans in pancreatic cancer. Histol Histopathol 2004;19:999-1011.

24 Fisher WE, Boros LG, Schirmer WJ: Insulin promotes pancreatic cancer: evidence for endocrine influence on exocrine pancreatic tumors. J Surg Res 1996;63:310-313.

25 Ding XZ, Fehsenfeld DM, Murphy LO, Permert J, Adrian TE: Physiological concentrations of insulin augment pancreatic cancer cell proliferation and glucose utilization by activating MAP kinase, PI3 kinase and enhancing GLUT-1 expression. Pancreas 2000;21:310-320.

-26 Federico A, Morgillo F, Tuccillo C, Ciardiello F, Loguercio C: Chronic inflammation and oxidative stress in human carcinogenesis. Int J Cancer 2007;121:2381-2386.

27 Ohshima H, Tatemichi M, Sawa T: Chemical basis of inflammation-induced carcinogenesis. Arch Biochem Biophys 2003;417:3-11.
28 Decensi A, Puntoni M, Goodwin P, Cazzaniga $\mathrm{M}$, Gennari A, Bonanni B, Gandini S: Metformin and cancer risk in diabetic patients: a systematic review and meta-analysis. Cancer Prev Res (Phila) 2010;3:14511461.

29 Hosono K, Endo H, Takahashi H, Sugiyama M, Sakai E, Uchiyama T, Suzuki K, Iida H, Sakamoto Y, Yoneda K, Koide T, Tokoro C, Abe $\mathrm{Y}$, Inamori $\mathrm{M}$, Nakagama $\mathrm{H}$, Nakajima A: Metformin suppresses colorectal aberrant crypt foci in a short-term clinical trial. Cancer Prev Res (Phila) 2010;3:1077-1083.

30 Pollak M: Metformin and other biguanides in oncology: advancing the research agenda. Cancer Prev Res (Phila) 2010;3:1060-1065.

31 Lai SW, Chen PC, Liao KF, Muo CH, Lin CC, Sung FC: Risk of hepatocellular carcinoma in diabetic patients and risk reduction associated with anti-diabetic therapy: a population-based cohort study. Am J Gastroenterol 2012;107:46-52.

32 Bowker SL, Majumdar SR, Veugelers P, Johnson JA: Increased cancer-related mortality for patients with type 2 diabetes who use sulfonylureas or insulin. Diabetes Care 2006;29: 254-258

-33 Giovannucci E: Insulin, insulin-like growth factors and colon cancer: a review of the evidence. J Nutr 2001;131:3109S-3120S.

>34 Furberg AS, Veierod MB, Wilsgaard T, Bernstein L, Thune I: Serum high-density lipoprotein cholesterol, metabolic profile, and breast cancer risk. J Natl Cancer Inst 2004; 96:1152-1160.

>35 Michalaki V, Koutroulis G, Syrigos K, Piperi C, Kalofoutis A: Evaluation of serum lipids and high-density lipoprotein subfractions (HDL2, HDL3) in postmenopausal patients with breast cancer. Mol Cell Biochem 2005; 268:19-24.

-36 Hammarsten J, Hogstedt B: Clinical, haemodynamic, anthropometric, metabolic and insulin profile of men with high-stage and high-grade clinical prostate cancer. Blood Press 2004;13:47-55.

$>37$ Feingold KR, Soued M, Adi S, Staprans I, Shigenaga J, Doerrler W, Moser A, Grunfeld C: Tumor necrosis factor-increased hepatic very-low-density lipoprotein production and increased serum triglyceride levels in diabetic rats. Diabetes 1990;39:1569-1574.

-38 Hardardottir I, Grunfeld C, Feingold KR: Effects of endotoxin and cytokines on lipid metabolism. Curr Opin Lipidol 1994;5:207-215.

>39 Oh HY, Lee EJ, Yoon S, Chung BH, Cho KS, Hong SJ: Cholesterol level of lipid raft microdomains regulates apoptotic cell death in prostate cancer cells through EGFR-mediated Akt and ERK signal transduction. Prostate 2007;67:1061-1069.

-40 Zhuang L, Lin J, Lu ML, Solomon KR, Freeman MR: Cholesterol-rich lipid rafts mediate Akt-regulated survival in prostate cancer cells. Cancer Res 2002;62:2227-2231. 
41 Van Hemelrijck M, Walldius G, Jungner I, Hammar N, Garmo H, Binda E, Hayday A, Lambe M, Holmberg L: Low levels of apolipoprotein A-I and HDL are associated with risk of prostate cancer in the Swedish AMORIS study. Cancer Causes Control 2011;22: 1011-1019.

-42 Calabresi L, Rossoni G, Gomaraschi M, Sisto F, Berti F, Franceschini G: High-density lipoproteins protect isolated rat hearts from ischemia-reperfusion injury by reducing cardiac tumor necrosis factor- $\alpha$ content and enhancing prostaglandin release. Circ Res 2003;92:330-337.

43 Han C, Zhang HT, Du L, Liu X, Jing J, Zhao $X$, Yang X, Tian B: Serum levels of leptin, insulin, and lipids in relation to breast cancer in china. Endocrine 2005;26:19-24.

-44 Zhang Z, Bast RC Jr, Yu Y, Li J, Sokoll LJ, Rai AJ, Rosenzweig JM, Cameron B, Wang YY, Meng XY, Berchuck A, Van Haaften-Day C, Hacker NF, de Bruijn HW, van der Zee AG, Jacobs IJ, Fung ET, Chan DW: Three biomarkers identified from serum proteomic analysis for the detection of early stage ovarian cancer. Cancer Res 2004;64:5882-5890.

45 Maisonneuve P, Lowenfels AB, Bueno-deMesquita HB, Ghadirian P, Baghurst PA, Zatonski WA, Miller AB, Duell EJ, Boffetta P, Boyle P: Past medical history and pancreatic cancer risk: results from a multicenter casecontrol study. Ann Epidemiol 2010;20:9298.

-46 Bracci PM, Wang F, Hassan MM, Gupta S, Li D, Holly EA: Pancreatitis and pancreatic cancer in two large pooled case-control studies. Cancer Causes Control 2009;20:17231731.

-47 Nitsche C, Simon P, Weiss FU, Fluhr G, Weber E, Gartner S, Behn CO, Kraft M, Ringel J, Aghdassi A, Mayerle J, Lerch MM: Environmental risk factors for chronic pancreatitis and pancreatic cancer. Dig Dis 2011;29: 235-242.
48 Lohr M, Kloppel G, Maisonneuve P, Lowenfels AB, Luttges J: Frequency of K-ras mutations in pancreatic intraductal neoplasias associated with pancreatic ductal adenocarcinoma and chronic pancreatitis: a metaanalysis. Neoplasia 2005;7:17-23.

-49 Yanagisawa A, Ohtake K, Ohashi K, Hori M Kitagawa T, Sugano H, Kato Y: Frequent cKi-ras oncogene activation in mucous cell hyperplasias of pancreas suffering from chronic inflammation. Cancer Res 1993;53 953-956.

50 Rivera JA, Rall CJ, Graeme-Cook F, Fernandez-del Castillo C, Shu P, Lakey N, Tepper R, Rattner DW, Warshaw AL, Rustgi AK: Analysis of K-ras oncogene mutations in chronic pancreatitis with ductal hyperplasia. Surgery 1997;121:42-49.

51 Ji B, Tsou L, Wang H, Gaiser S, Chang DZ, Daniluk J, Bi Y, Grote T, Longnecker DS, Logsdon CD: Ras activity levels control the development of pancreatic diseases. Gastroenterology 2009;137:1072-1082.e6.

52 Thomsen RW, Thomsen HF, Norgaard M, Cetin K, McLaughlin JK, Tarone RE, Fryzek JP, Sorensen HT: Risk of cholecystitis in patients with cancer: a population-based cohort study in Denmark. Cancer 2008;113: 3410-3419.

53 Silverman DT, Schiffman M, Everhart J, Goldstein A, Lillemoe KD, Swanson GM, Schwartz AG, Brown LM, Greenberg RS, Schoenberg JB, Pottern LM, Hoover RN, Fraumeni JF Jr: Diabetes mellitus, other medical conditions and familial history of cancer as risk factors for pancreatic cancer. Br J Cancer 1999;80:1830-1837.

54 Wang DS, Chen DL, Ren C, Wang ZQ, Qiu MZ, Luo HY, Zhang DS, Wang FH, Li YH, $\mathrm{Xu}$ RH: Abo blood group, hepatitis B viral infection, and risk of pancreatic cancer. Int J Cancer 2012;131:461-468.
55 Hardt PD, Bretz L, Krauss A, SchnellKretschmer H, Wusten O, Nalop J, Zekorn T, Klor HU: Pathological pancreatic exocrine function and duct morphology in patients with cholelithiasis. Dig Dis Sci 2001;46:536539.

56 Olsen TS: The incidence and clinical relevance of chronic inflammation in the pancreas in autopsy material. Acta Pathol Microbiol Scand A 1978;86A:361-365.

57 Doerr W: Pathogenesis of acute and chronic pancreatitis (in German). Verh Dtsch Ges Inn Med 1964;70:718-758.

$\checkmark 58$ Ye W, Lagergren J, Nyren O, Ekbom A: Risk of pancreatic cancer after cholecystectomy: a cohort study in Sweden. Gut 2001;49:678681.

59 Ekbom A, Yuen J, Karlsson BM, McLaughlin JK, Adami HO: Risk of pancreatic and periampullar cancer following cholecystectomy: a population-based cohort study. Dig Dis Sci 1996;41:387-391.

60 Shibata A, Mack TM, Paganini-Hill A, Ross RK, Henderson BE: A prospective study of pancreatic cancer in the elderly. Int J Cancer 1994;58:46-49.

61 Haddock G, Carter DC: Aetiology of pancreatic cancer. Br J Surg 1990;77:1159-1166.

62 Smith JP, Solomon TE, Bagheri S, Kramer S: Cholecystokinin stimulates growth of human pancreatic adenocarcinoma SW-1990. Dig Dis Sci 1990;35:1377-1384.

63 Axelson J, Ihse I, Hakanson R: Pancreatic cancer: The role of cholecystokinin? Scand J Gastroenterol 1992;27:993-998.

64 Fuchs CS, Colditz GA, Stampfer MJ, Giovannucci EL, Hunter DJ, Rimm EB, Willett WC, Speizer FE: A prospective study of cigarette smoking and the risk of pancreatic cancer. Arch Intern Med 1996;156:2255-2260.

65 Nilsen TI, Vatten LJ: A prospective study of lifestyle factors and the risk of pancreatic cancer in Nord-Trondelag, Norway. Cancer Causes Control 2000;11:645-652. 